\title{
Who's assessing needs-led assessment?
}

\author{
Peter H. Dick, David Reid, Audrey Simpkins and Tessa Durham
}

\begin{abstract}
Pre- and post-change audits of the effect of the changes in community care assessments and funding intro-duced in April 1993 were carried out on a psychiatric in-patient rehabllitation unit in Dundee. There was a substantial reduction in throughput in the rehabilitation unit (from $\mathbf{4 3}$ to 22) and in placements to funded staffed accommodation (from 11 to three) desplite an increase in void community tenancies. By three months, 17 of 22 referrals for needs assessment were still incomplete, and at one year only three patients had had their needs assessed and appropriately met. Recommendations arising from these findings are discussed.
\end{abstract}

In a previous study we demonstrated that up to half of the time spent in a rehabilitation ward was unnecessary and due in large part to delays in obtaining adequately staffed community accommodation (Dick et al, 1992). The community care changes introduced in April 1993 set out to improve assessment and, by making the money follow the patient, improve flexibility (Department of Health, 1989). We decided, therefore, to audit the effect of the new needs-led assessment procedure (based on a comprehensive social work led assessment of client need prior to placement) and the new funding arrangements on the same in-patient rehabilitation unit.

\section{The study}

Changes in the referral and assessment process resulting from the community care changes were documented. In the year prior to the introduction of community care (April 1992 to March 1993) and in the year following its introduction (April 1993 to March 1994) data were collected on the total number of discharges and the number of discharges to staffed accommodation funded through the Department of Social Security in $1992-1993$ or directly by Social Work in 19931994. (Social Work in Scotland is equivalent to Social Services in England and Wales.) A census was conducted at the end of each year covering the number of patients in the ward, the number assessed and waiting for supported accommodation, and the number of vacant places in dedicated staffed accommodation in the commu- nity (accommodation with 24-hour cover, predominantly for people suffering from mental illness).

A record was also kept of all referrals to the new needs-led assessment process in the year following its introduction and of the outcome of the assessment at three months and one year. It was possible to follow $59 \%$ of cases up to two years.

\section{Findings}

Changes in the referral and assessment process

In the old system a single social worker from a team of five was attached to the ward team on a part-time basis as a valued member. He or she did casework over discharge on selected patients and also advised other staff on accommodation and procedures. Suitable candidates were identified, based on the rehabilitation team's assessment of need, the patient's choice, and on the assessment of the proposed receiving setting. In the new system there is no decrease in the number of social workers, but a referral by the ward team to the Social Work Department may now be picked up by any one of the five social workers, neither side being familiar with each other's working practices. The social workers have been split into separate assessment and care management, and resource provision teams. The ward team is discouraged from making a recommendation on placement as the social worker is expected to carry out the assessment of need and come to his or her own conclusion. The assessment is estimated to take 15-30 hours.

\section{Changes in referral and disposal patterns}

Forty-three patients were discharged in 1992-93 and 22 in 1993-94; there were 17 patients in the rehabilitation ward in March 1993 and 21 in March 1994; 22 patients were referred for needs assessment in 1993-94. Taking into account overlap among these groups the total number of individual patients involved in the study was 58 ; of these $41(71 \%)$ were male, $35(60 \%)$ were aged 
under 45, and 41 (71\%) were suffering from schizophrenia.

Table 1 demonstrates a substantial reduction in throughput in the rehabilitation unit and in placements to funded staffed accommodation in the year following the introduction of community care. At the end of the second year the number of patients waiting for such accommodation was also higher, despite there being a higher number of void tenancies (seven out of 51 places compared with one in the first year).

\section{Outcomes of assessments of need}

As written assessments specifying either recommended placement or documenting unmet need were obtained in only a minority of cases, the outcomes given in Table 2 are primarily based on the ward team's opinion informed by discussion with the care manager. One year after referral for assessment, 19 of the 22 patients were still assessed as suitable for discharge yet only three had had their needs assessed and appropriately met in the community. There had been significant fluctuations in mental state in seven of these patients which had complicated, but need not have prevented, assessment and placement. Of the nine patients in the unmet need group, only three had had their unmet need formally documented by the care manager. It was possible to follow the first 13 referrals up to two years: unmet need had still not been formally documented in three of the eight cases in the unmet need group.

\section{Comments}

Government policy has emphasised the importance of needs-led assessment within a system of care management (Department of Health, 1989) but recent leaders have described care management as a "disastrous mistake" (Lancet, 1995) and a "dubious practice" (Marshall, 1996). In Dundee the introduction of the approach

Table 1. Rehabilitation in-patients 1992-93 v. 1993-94

\begin{tabular}{llc}
\hline & $1992-93$ & $1993-94$ \\
\hline Discharges in preceding year & & \\
total & 43 & 22 \\
new to DSS/SW funded & 11 & 3 \\
$\quad$ accommodation & & \\
End year census & & \\
$\quad$ (22 available places) & 17 & 21 \\
total & 2 & 11 \\
$n$ waiting for funded & & \\
$\quad$ accommodation & & \\
\hline
\end{tabular}

Table 2. Outcome of needs assessment referrals 1993-1994 $(n=22)$

\begin{tabular}{lll}
\hline & 3 & 1 \\
& months & year \\
\hline In-patient & 17 & 1 \\
Assessment incomplete & 2 & 4 \\
Assessed - waiting for place & 0 & 9 \\
Assessed - no appropriate facility & 0 & 3 \\
Definitely requiring continued IP & 0 & \\
$\quad$ care & & \\
Community & 1 & 3 \\
Support in line with assessed need & 1 & 2 \\
Support less than assessed need & 2 & \\
\hline
\end{tabular}

appears to have had effects diametrically opposed to those intended. Delays in arranging and implementing assessments have led to inefficient use of resources through unnecessarily prolonged hospitalisation even when alternative community facilities exist. Reduced throughput in the rehabilitation ward has also blocked acute beds, denying access to seriously ill patients in the community, an outcome foreseen by Thornicroft et al (1993). The Dundee Healthcare NHS Trust, providing a comprehensive psychiatric service to its compact city catchment of 160000 , is similar to many around the country. It is not possible to generalise from a single study, but if the Dundee experience has been replicated in even a minority of services elsewhere, then the consequences of protracted delay for patients and inefficient use of resources nationally would be considerable. An alternative explanation for the delays in throughput in the second year of this study is that easier to place patients were discharged in the first year, leaving a hard core of difficult to place patients in year two. However, for over a decade the Dundee unit has catered predominantly for convalescent acute in-patients and direct community admissions, and has maintained a stable admissiondischarge pattern (Dick, 1990). This, coupled with the fact that the staffed housing units had been in place for a number of years, makes such an explanation unlikely.

Teething problems with the new procedure were clearly to be expected, but the duration of the resultant problems identified suggests underlying flaws in the operational procedure. The absence of any effective remedial action at local or national level suggests that existing standard setting and monitoring arrangements need to be improved. The case for carrying out controlled evaluations of needs-led assessment and care management appears to be very strong. 
AUDIT

Comparison between the old and new social services system

In the original system in Dundee good links were built up between the rehabilitation service and the staffed accommodation units. It could be anticipated when a place was likely to come up. and when a patient's mental state changed another candidate could readily be identified and put forward. There were no complications with funding as it was linked to the vacant place. Optimum use was therefore made of existing resources through a flexible needs resource matching process rather than through needs assessment in isolation. In the new system, as the assessment team is primarily involved in assessment for social work funded accommodation and has to pass ongoing casework on to the resource team, there has been a substantial reduction in the availability of skilled social work time for casework. Also the time allocated to assessment duplicates the ward team efforts. Temporary fluctuations in patients' mental state and difficulties in negotiating funding processes delay placement by months or longer, even when there is a vacant place available. The process has therefore become duplicative and inefficient.

\section{Separating care management from clinical work}

Varying models of needs-led assessment and care management are being implemented in different parts of the country. Although Scottish services, like those in England, are being encouraged to focus services more systematically on the most ill through the Care Programme Approach, the central drive in Scotland has to date been less forceful and the guidelines on responsibility more ambiguous. Detailed guidelines on care management in Scotland have advocated that it is "a separate process from service provision and the two types of activity need to be distinguished. It can be seen as a system of brokerage" (Scottish Office, 1991). The changes introduced by the Social Work Deparment in Tayside have therefore been in line with Government policy, albeit with little flexdbility of interpretation. The contradiction inherent in detaching assessment and care management from the clinical team while still attempting to provide continuity of care has been discussed by Ryan (1993), who further observes that "the role of the care manager is a particularly critical issue for people experiencing long-term mental health difficulties". In our view, whatever the merits of splitting purchaser and provider functions administratively, with this patient group it is essential at a clinical level that assessment and ongoing clinical casework are carried out by the same individual and that assessment should be a continuous rather than intermittent process. It is also important to avoid wasteful duplication.

\section{Identification of unmet need}

Needs-led assessment has demonstrated that existing provision is inadequate for a substantial minority of patients being discharged from a rehabilitation ward in Dundee. As we previously demonstrated this in a study carried out a decade ago (Dick et al, 1992), however, it seems unlikely that demonstration of unmet need will itself produce change. In the current study the substantial delay in formally recording unmet need coupled with the apparent absence of individual or strategic action plans to address the unmet need confirms this view. For individual patients it is important that identification of unmet need is accompanied by the development of an action plan which takes account of available resources. In considering aggregated unmet need, as the specific grant system is inadequate to meet substantial staffed housing developments and as the bridging initiative is specifically attached to long-stay patients, it is suggested that a new central funding mechanism be developed to meet the needs of these transitional patients. Otherwise, if the Dundee experience is replicated elsewhere the potentially exciting community care initiative will flounder at the first hurdle of needs-led assessment.

\section{Acknowledgements}

We thank all patients and staff in the Rehabilitation Service and Staffed Accommodation Units for their constructive participation. The study was supported by a grant from the Tayside Area Medical Audit Committee.

\section{References}

Department of HEalth (1989) Caring for People: Community Care in the Next Decade and Beyond. London: HMSO.

Dick. P. H. (1990) Psychiatric in-patient rehabilitation: is there a future? International Journal of Rehabilitation Research, 13, 119-126.

-. Crombie, I. K., Durham, T., et al (1992) Unnecessary hospitalisation in a psychiatric rehabilitation unit. British Medical Journal, S04, 1544.

LANCET (1995) Care Management: a disastrous mistake. Lancet, 345, 399-401.

MARSHALL, M. (1996) Care management: a dubious practice. British Medical Journal, 312, 523-524.

RYAN, P. (1993) Social Services Care Management. In Dimensions of Community Mental Health Care leds M. Weller \& M. Mutjen). pp. 82-102. London: Balllière Tindall.

SCOTTISH OFFICE (1991) Development of Community Care: Care Programmes for People with a Mental Illness (including Dementia). Consultation Paper No. 6. Edinburgh: Scottish Office. 
THORNICROFT, G. WARD, P. \& JAMES, S. (1993) Care management and mental health. British Medical Joumal, s08, 768-771.

*Peter H. Dick, Consultant, Dundee Healthcare NHS Trust, Royal Dundee Liff Hospital, Dundee DD2 5NF, David Reid, Lecturer, University
Department of Psychiatry, Ninewells Hospital, Dundee; Audrey Simpkins, Charge Nurse, and Tessa Durham, Research Occupational Therapist, Royal Dundee Liff Hospital

*Correspondence

\title{
New from Gaskell
}

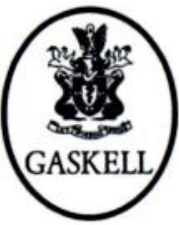

\section{Mental Disorders in China}

\author{
English Version Editors: John E. Cooper \& Norman Sartorius
}

This is the first available account in English of the results of the 1982 Chinese Epidemiological Survey of Mental Disorder. It is the only nationwide Chinese study to involve modern methods of case assessment and is uniquely large and interesting; 12 centres in different parts of China studied a rural and an urban sample of 500 households each, giving a total sample of 51982 persons. The use of the Present State Examination in the survey allows the symptomatic basis of diagnoses, such as neurasthenia, to be examined. The results indicate that the prevalence of schizophrenia is similar to that found recently in other countries, but that the prevalence of other mental disorders may be lower. Readers may also be interested to purchase Mental Health Care in China, published in 1995, price $\mathrm{E} / 2.50$.

\section{$\bullet$ Price $f 15.00 \bullet$ I28pp. $\bullet 1996 \bullet$ ISBN $090224 \mid 93$ I}

Available from good bookshops and from the Publications Department, Royal College of Psychiatrists, I7 Belgrave Square, London SWIX 8PG (Tel. 017 I-235 235I, extension I46) 